\title{
Polyethylene glycol-poly(e-benzyloxycarbonyl-L- lysine)-conjugated VEGF siRNA for antiangiogenic gene therapy in hepatocellular carcinoma
}

\author{
This article was published in the following Dove Press journal: \\ International Journal of Nanomedicine \\ 9 May 2017 \\ Number of times this article has been viewed
}

\author{
Gangmin Wang, ${ }^{1, *}$ XiaoLong \\ $\mathrm{Gao},{ }^{2, *}$ Guojun $\mathrm{Gu},{ }^{2}$ \\ ZhiHong Shao, ${ }^{2}$ MingHua \\ Li, ${ }^{2}$ PeiJun Wang, ${ }^{2}$ JianRong \\ Yang, ${ }^{3}$ XiaoJun Cai, ${ }^{4}$ \\ YongYong $\mathrm{Li}^{4}$ \\ 'Department of Urology, Huashan \\ Hospital, Fudan University, \\ ${ }^{2}$ Department of Radiology, Tongji \\ Hospital, School of Medicine, Tongji \\ University, Shanghai, ${ }^{3}$ Department \\ of Hepatobiliary Surgery, Third \\ People's Hospital of Guangxi Zhuang \\ Autonomous Region, Nanning, \\ ${ }^{4}$ Institute for Advanced Materials \\ and Nano Biomedicine, School of \\ Material Science and Engineering, \\ Tongji University, Shanghai, People's \\ Republic of China \\ *These authors contributed equally \\ to this work
}

\begin{abstract}
A polyethylene glycol-poly(e-benzyloxycarbonyl-L-lysine) (PEG-SS-PLL) block copolymer based on a disulfide-linked, novel biodegradable catiomer bearing a PEG-sheddable shell was developed to avoid "PEG dilemma" in nanoparticle intracellular tracking of PEG-PLL where PEG was nondegradable. However, PEG-SS-PLL catiomers have not been used to deliver small interfering VEGF RNA (siVEGF) in antiangiogenesis gene therapy. In this study, we aimed to investigate whether this novel biodegradable catiomer can deliver siVEGF into cancer cells and at the same time have an antitumor effect in a xenograft mouse model. It was found that PEG-SSPLL efficiently delivered siVEGF with negligible cytotoxicity, and significantly decreased the expression of VEGF at both the messenger-RNA and protein levels both in vitro and in vivo, and thus tumor growth was inhibited. Our findings demonstrated that PEG-SS-PLL/siVEGF could potentially be applied to antiangiogenesis gene therapy for hepatocellular carcinoma.
\end{abstract}

Keywords: polyethylene glycol, poly lysine, disulfide, VEGF, antiangiogenesis, hepatocellular carcinoma, siRNA

\section{Introduction}

Hepatocellular carcinoma (HCC) is one of the five most common cancers and the third leading cause of cancer death worldwide, with approximately 700,000 new cases annually. ${ }^{1,2}$ Despite great advances in HCC diagnosis and therapy, the mortality rate remains high, especially for $\mathrm{HCC}$ in the advanced stage, when the disease is usually diagnosed. ${ }^{3}$ Curative treatments currently available for HCC include surgical approaches, such as resection and transplantation, percutaneous ablation, and chemoembolization. However, none of them is effective for all patients, and studies have shown that patients with HCC have an average life expectancy of about 6 months after diagnosis. ${ }^{4}$ It is well known that $\mathrm{HCC}$ is one of the most vascular solid tumors and that angiogenesis plays an important role in the development, progression, and metastasis of the tumor..$^{5}$ Accordingly, the inhibition of tumor angiogenesis by novel agents has become a very active field in antitumor research. VEGF expression is low in normal tissue, but is extremely high in liver cancer tissue with the expansion of tumor tissue. ${ }^{6}$ VEGF serves as a useful biological marker of liver cancer aggression and metastasis, because it is mainly expressed in tumor cells and endothelial cells. It plays a key role in the metastasis and prognosis of primary liver cancer. ${ }^{7-10}$ Among numerous growth factors involved in angiogenesis, VEGF is thought to be the most significant. ${ }^{11}$ 
Small interfering RNA (siRNA), capable of mediating transcript degradation for specific gene silencing, ${ }^{12}$ has recently emerged as a promising candidate for the treatment of numerous diseases, including neurodegenerative disorders, cancers, and infectious diseases. ${ }^{13-16}$ Therefore, VEGF siRNA (siVEGF) has been applied in antiangiogenic therapy in HCC with therapeutic potential. ${ }^{6,17,18}$ However, inefficient siRNA delivery to the cytoplasm of HCC cells remains a major obstacle for more widespread adoption of siRNA-based gene therapy. ${ }^{19}$

Surface functionalization with polyethylene glycol (PEG) has become a preferred coating strategy to prolong the in vivo circulation time of nanoparticle drug-delivery systems by reducing siRNA degradation, macrophage uptake, and particle aggregation. ${ }^{20,21}$ However, PEG may become a detriment once it reaches target tissue, because it hinders the entry of nanoparticles into cells or prevents their escape from the endosome after endocytosis. ${ }^{22}$ To solve these issues, PEG shedding in response to intracellular environments has been proposed. ${ }^{23-25}$ More recently, a novel biocompatible and biodegradable PEG-polypeptide catiomers bearing a PEG-sheddable shell and a disulfide-linked
PEG-poly( $\varepsilon$-benzyloxycarbonyl-L-lysine) block copolymer (PEG-SS-PLL) was developed in our laboratory. It was found that the PEG-SS-PLL catiomer effectively delivered plasmid DNA into HeLa cells in vitro with negligible cytotoxicity. ${ }^{26-28}$ However, there have been no studies regarding PEG-SSPLL-mediated siVEGF delivery into cancer cells and the antitumor effect of siVEGF. ${ }^{29}$ In this study, we aimed to investigate whether this novel biodegradable catiomer was capable of delivering siVEGF into cancer cells and had an antitumor effect in a xenograft mouse model, as in Scheme 1. Our findings demonstrated that PEG-SS-PLL efficiently delivered siVEGF into HepG2 cells or HepG2 xenograft, decreased the levels of both VEGF messenger RNA (mRNA) and protein expression, and thus significantly inhibited tumor cells and tissue growth in vitro and in vivo, respectively. This indicated that PEG-SS-PLL catiomer could be potentially applied to deliver siVEGF in the antiangiogenic treatment of HCC.

\section{Materials and methods}

Dulbecco's Modified Eagle's Medium, penicillinstreptomycin, trypsin-like enzyme (TrypLE Express), and

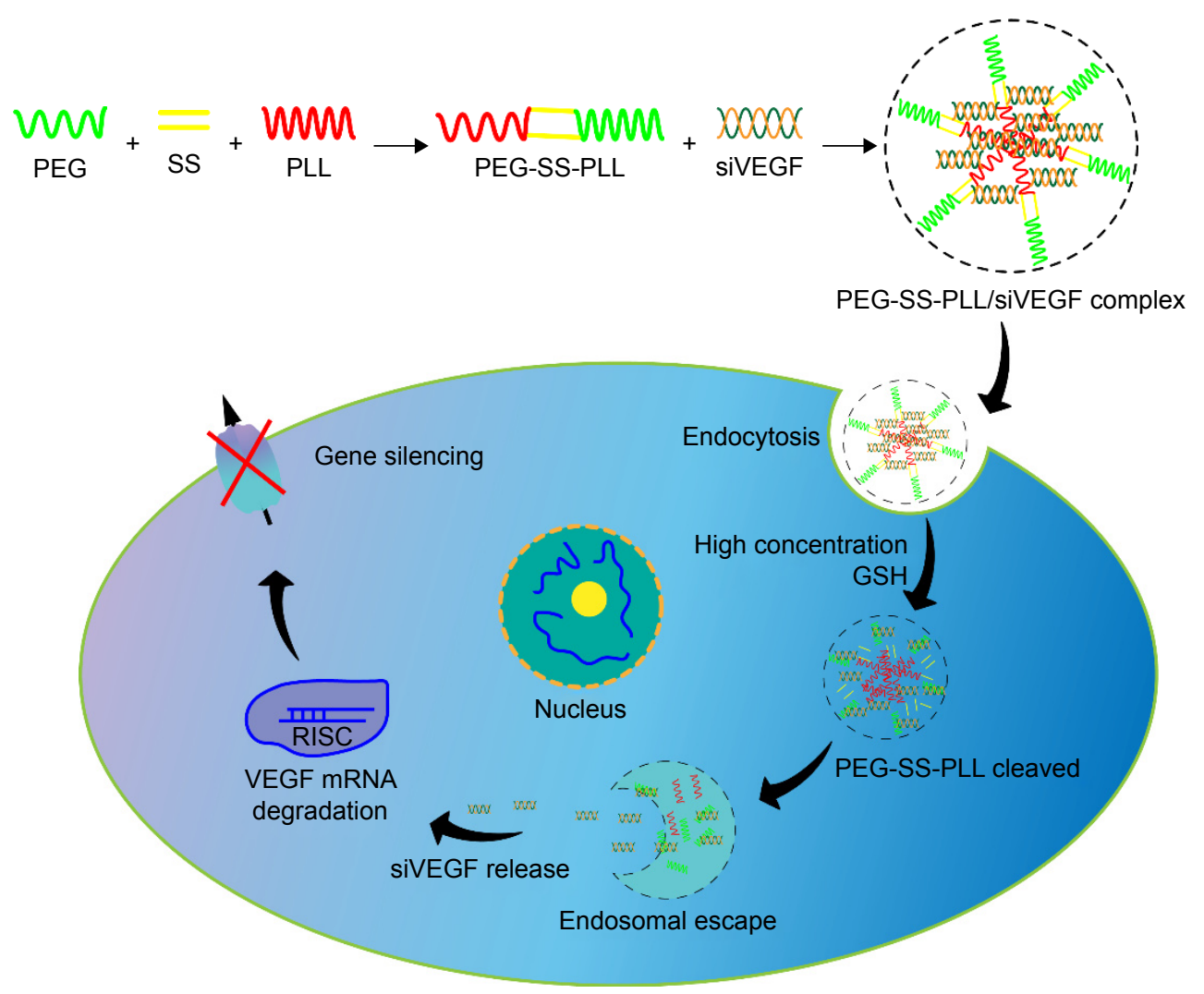

Scheme I Illustration of PEG-SS-PLL catiomer for siVEGF encapsulation and intracellular stimulus-responsive siVEGF release.

Abbreviations: PEG-SS-PLL, polyethylene glycol-poly(ع-benzyloxycarbonyl-L-lysine); siVEGF, small interfering VEGF RNA; GSH, glutathione; RISC, RNA-induced silencing complex; mRNA, messenger RNA. 
Dulbecco's phosphate-buffered saline (PBS) were purchased from Thermo Fisher Scientific (Waltham, MA, USA). $N$-Hydroxysuccinimide-vinyl sulfone PEG (molecular weight 3,400 Da) was obtained from Nektar (Huntsville, AL, USA). RGD peptide was bought from Genemed Synthesis (San Antonio, TX, USA). Peptides were purified via reversephase high-performance liquid chromatography and then analyzed by mass spectrometry performed using matrix-assisted laser desorption/ionization time-of-flight mass spectrometry. Fetal bovine serum (FBS) was bought from GE Healthcare (Little Chalfont, UK). siVEGF was obtained from GenePharma (Shanghai, People's Republic of China [PRC]). The HepG2 cell line was purchased from the American Type Culture Collection (Manassas, VA, USA).

\section{Cell culture and transfection}

HepG2 cells were cultured in Dulbecco's Modified Eagle's Medium supplemented with $10 \% \mathrm{FBS}$ and $100 \mathrm{U} / \mathrm{mL}$ penicillin-streptomycin at $37^{\circ} \mathrm{C}$ in a humidified atmosphere with $5 \% \mathrm{CO}_{2}$. The cells $\left(5 \times 10^{4}\right.$ cells/well $)$ were plated in 24-well plates and allowed to grow for 24 hours to reach $70 \%$ confluence.

\section{MTT assay for cell viability}

HepG 2 cells $\left(5 \times 10^{3}\right.$ cells/well) were seeded in 96-well plates and allowed to grow for 24 hours to reach $70 \%$ confluence. PEG-SS-PLL/siVEGF, PEG-PLL/siVEGF, polyethylenimine (PEI)/siVEGF, and Lipofectamine/siVEGF complexes were mixed at different ratios of vector to $\operatorname{siVEGF}(0,0.1,0.2,0.4$, $0.6,0.8,1$, and 1.2). The HepG2 cells were transfected with PEG-SS-PLL/siVEGF, PEG-PLL/siVEGF, PEI/siVEGF, or Lipofectamine/siVEGF at different concentrations (50, 100, 150 , or $200 \mathrm{nM}$ ) or PBS for 48 hours, followed by a typical siRNA-transfection experiment, ${ }^{30}$ and cell viability was evaluated by MTT assay. In brief, $20 \mu \mathrm{L}$ of MTT solution at $5 \mathrm{mg} / \mathrm{mL}$ (Thermo Fisher Scientific) was added to each well and incubated with the cells for 4 hours, then, the medium was removed and $150 \mu \mathrm{L}$ of dimethyl sulfoxide added to each well. The absorbance (optical density) was measured at $570 \mathrm{~nm}$ using a plate reader (Thermo Fisher Scientific). Cell viability was calculated as percentage of live cell numbers to the PBS-transfected cell numbers. Each treatment was carried out in triplicate.

\section{Agarose gel-retardation assay}

To assess the siVEGF-condensation ability of the catiomer, an agarose gel-retardation assay was performed. PEG-SSPLL/siVEGF complexes were mixed with different weight ratios of PEG-SS-PLL to siVEGF $(0,0.1,0.2,0.4,0.6,0.8$, 1 , and 1.2). Afterward, the complex $(6 \mu \mathrm{L})$ containing $0.1 \mu \mathrm{g}$ siVEGF was electrophoresed onto 1\% (w:v) agarose gel containing ethidium bromide. Electrophoresis was carried out at $120 \mathrm{~V}$ for 30 minutes in Tris-acetate running buffer. The siVEGF bands were visualized under an ultraviolet lamp and analyzed using an image-based gel documentation system.

\section{Particle size and $\zeta$-potential measurements}

Particle size and $\zeta$-potential of PEG-SS-PLL/siVEGF complexes were measured using a Nano ZS 90 Zetasizer (Malvern Instruments, Malvern, UK). The complex was mixed as diluted with $150 \mathrm{mM} \mathrm{NaCl}$ solution to $1 \mathrm{~mL}$ prior to measurement. The morphology of PEG-SS-PLL/siVEGF complexes was observed by high-resolution transmission electron microscopy (TEM; H-7100; Hitachi, Tokyo, Japan). The size distribution, $\zeta$-potential, storage stability, and glutathione (GSH) response of the complex was recorded by the Nano ZS 90 Zetasizer.

\section{Effect of GSH on stability of PEG-SS-PLL/ siVEGF complex}

Stability testing was performed by measuring the size changes of the PEG-SS-PLL/siVEGF complex at different time intervals. In order to investigate the effect of serum on the stability of the complex, we added $10 \%$ FBS into the complex solution. The protocol used to assess the stability of the PEG-SS-PLL/siVEGF complex in response to GSH has been described elsewhere. ${ }^{27} \mathrm{GSH}$ was added to a diluted solution of PEG-SS-PLL/siVEGF complex containing 10\% FBS to reach a final concentration of $10 \mathrm{mM} \mathrm{GSH}$. The size change of the complex was monitored by dynamic light scattering.

\section{Evaluation of transfection efficiency of PEG-SS-PLL/siVEGF complex}

In order to visualize transfection efficiency, siRNA was labeled with FAM at the $5^{\prime}$ end of the siRNA. HepG2 cells were trypsinized with $0.25 \%$ trypsin and seeded at a density of $5 \times 10^{4}$ cells per well in 24-well culture plates and incubated overnight. The media were removed and $150 \mu \mathrm{L}$ of serum-free Opti-MEM or serum-containing media added. Then, siRNA alone, Lipofectamine/siVEGF, PEG-PLL/ siVEGF, or PEG-SS-PLL/siVEGF was added to the cells to be continuously incubated for 24 hours. The cultured HepG2 cells were examined by fluorescence microscopy and flow cytometry. 


\section{Cell apoptosis detection by flow cytometry}

siRNA transfection was performed according to the aforementioned procedure. At 48 hours posttransfection, transfected cells were trypsinized, collected, and washed twice with prechilled PBS. Then, cells were stained with annexin V-fluorescein isothiocyanate (FITC) and propidium iodide (PI) using an annexin V-FITC apoptosis detection kit (BD Biosciences, San Jose, CA, USA). Apoptosis of each transfection was assayed three times. The percentage of apoptotic cells was quantified by flow cytometry (BD Biosciences). Annexin V-FITC-positive and PI-negative signals indicated early apoptosis, while annexin V-FITC-positive and PIpositive signals indicated late apoptosis.

\section{Tumor model and siVEGF treatment in vivo}

BALB/c nude mice (5-6 weeks old) were purchased from the Shanghai Experimental Animal Centre of the Chinese Academy of Sciences (Shanghai, PRC). All methods used in this study were approved by the Animal Care and Use Committee at Tongji University and were carried out in accordance with the guidelines of the Institutional Animal Care and Use Committee and National Research Council (USA) Committee. ${ }^{31,32}$ The animals were divided into the following five groups, with five mice in each group: model group, PBS group, PEG-SS-PLL/siLuc group (siLuc represented negative control), PEG-PLL/siVEGF group, and PEG-SS-PLL/siVEGF group. HepG2 tumors were induced in the mice by subcutaneously injecting HepG2 cells $\left(5 \times 10^{6}\right)$ into their flanks. When the tumor volume reached approximately $200 \mathrm{~mm}^{3}$, the mice were intravenously injected five times every other day with PEG-SS-PLL/siLuc, PEG-PLL/ siVEGF, or PEG-SS-PLL/siVEGF containing $20 \mu \mathrm{g}$ of siVEGF per mouse or injected with PBS. Tumor size was monitored every 3 days. The tumor volume was measured with digital calipers in two dimensions and calculated according to the formula (length) $\times(\text { width })^{2} / 2$.

\section{Quantification of intracellular and intratumoral VEGF mRNA}

Cells were collected at 48 hours after siRNA complex transfection, as mentioned earlier. Total RNA was isolated by a Trizol reagent kit (Thermo Fisher Scientific). Complementary DNA (cDNA) was synthesized with a first-strand cDNAsynthesis kit (RevertAid; Thermo Fisher Scientific). In brief, an aliquot of $1 \mu \mathrm{g}$ of total RNA was reverse transcribed by Moloney Murine Leukemia Virus (MMLV) transcriptase
(Thermo Fisher Scientific) using random hexamer primers according to the manufacturer's instructions. The reaction system for real-time quantitative polymerase chain reaction (qPCR; TransStart gene qPCR SuperMix; TransGen Biotech, Beijing, PRC) with an SYBR Green I probe was $12.5 \mu \mathrm{L}$ of $2 \times$ TransStar green qPCR SuperMix, $0.5 \mu \mathrm{L}$ of $10 \mu \mathrm{M}$ of each primer, $0.5 \mu \mathrm{L}$ of passive reference dye, $2 \mu \mathrm{L}$ of cDNA, and $25 \mu \mathrm{L}$ of nuclease-free water. For siVEGF, the sense primer sequence was 5'-CTACGGCGACATGGAGAACAAGC-3', and the anti-sense primer sequence was $5^{\prime}$-CGCAGCCATACT CAGGGACAC- $3^{\prime}$. For $\beta$-actin, the sense primer sequence was 5'-CCTGGCACCCAGCACAATGAAG-3', and the anti-sense primer sequence was $5^{\prime}$-GGGGCCGGACTCGT CATACTC-3' (Sangon Biotech, Shanghai, PRC). Reaction parameters were $95^{\circ} \mathrm{C}$ for 30 seconds, then $72^{\circ} \mathrm{C}$ for 60 seconds, for 40 cycles. Relative gene expression of siVEGF was calculated based on the $2^{-\Delta \Delta C T}$ method with a reference gene of $\beta$-actin.

\section{Quantification of intracellular and intratumoral VEGF proteins}

To determine the amount of VEGF in each solid-tumor region, tumors were harvested from the tumor-bearing mice 3 days after final treatment of the siRNA complex. The tumors were weighed and homogenized in PBS using an electronic tissue homogenizer (Kinematica AG, Lucerne, Switzerland). The tissue homogenates were centrifuged at $3,000 \mathrm{rpm}$ at $4^{\circ} \mathrm{C}$ for 5 minutes, and the supernatant was used for further analysis. The amount of VEGF was determined by enzymelinked immunosorbent assay (ELISA) according to the manufacturer's instruction using a human VEGF-immunoassay kit (Quantikine; R\&D Systems, Minneapolis, MN, USA).

\section{Immunohistochemistry analysis}

Sections $4 \mathrm{~mm}$ thick were stained with the primary antibodies rabbit antimouse VEGFA (diluted 1:10,000), rat antimouse CD31 (diluted 1:10,000), or rabbit antimouse LYVE1 (diluted 1:10,000; Abcam, Cambridge, UK) and then a poly-horseradish peroxidase detection system (Zhongshan Biotechnology, Beijing, PRC). The color was developed with 3,30-diaminobenzidine according to the manufacturer's instructions.

Tumor specimens were sectioned and stained routinely with either hematoxylin and eosin or CD31, a proliferation marker. Tumor sections were stained for VEGF with VectaStain Elite ABC kit (Vector Laboratories, Burlingame, CA, USA) and rabbit anti-Ki67 primary antibody, followed by counterstaining of nuclei with hematoxylin. 
Paraffin slices were treated with a streptavidin-biotin complex immunohistochemical kit, and results were analyzed based on a double-blind method. Five high-power fields (400×) were randomly selected, and results were evaluated by two pathologists independently. PBS instead of the primary antibody was used as negative control, and specimens were scored according to the intensity of the dye color and the number of positive cells. The intensity of the dye color was graded as 0 (no color), 1 (light yellow), 2 (light brown), or 3 (brown), and the number of positive cells was graded as $0(<5 \%), 1(5 \%-25 \%)$, $2(25 \%-50 \%), 3(51 \%-75 \%)$, or $4(>75 \%)$. The two grades were combined together and specimens assigned to one of 4 levels: scores of $0-1(-), 2(+), 3-4(++)$, and more than $5(+++)$. The positive-expression rate is expressed as the percentage of the addition of $(++)$ and $(+++)$ to the total number.

\section{Statistical analysis}

All data were analyzed with SPSS version 19.0 software. Results are expressed as mean \pm standard deviation. Statistical differences between groups were calculated using one-way analyses of variance and Dunnett's test, and $P<0.05$ was considered statistically significant.

\section{Results \\ Cell viability}

Cellular toxicity of PEG-SS-PLL was examined by MTT assay, and the results were compared to those of the PEG-PLL and the blank control (Figure 1). The results showed that HepG2 cells posttreatment with either PEG-PLL or PEG-SS-PLL at

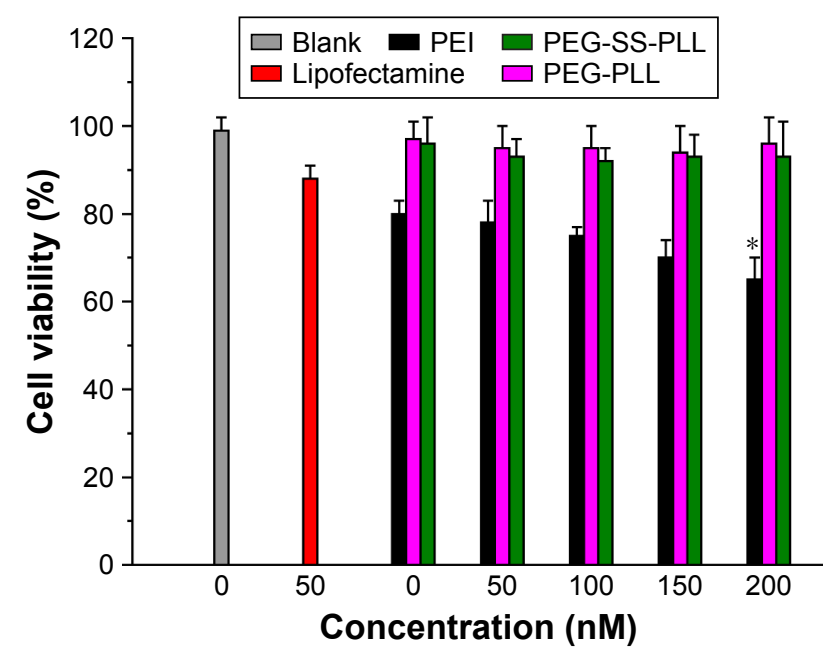

Figure I HepG2 cell viability posttreatment with PEI, Lipofectamine, PEG-PLL, or PEG-SS-PLL at various concentrations or mock treatment of PBS.

Notes: $* P<0.05$. Data expressed as mean \pm SD of three experiments. Cell viability was determined relative to the blank group.

Abbreviations: PEI, polyethylenimine; PEG-SS-PLL, polyethylene glycol-poly $(\varepsilon-$ benzyloxycarbonyl-L-lysine); PBS, phosphate-buffered saline; SD, standard deviation. various concentrations ( $0-200 \mathrm{nM}$ ) for 48 hours resulted in no significant cell death, even at a concentration of $200 \mathrm{nM}$. However, cell viability after treatment with either PEI or Lipofectamine significantly decreased at concentrations of 50-200 nM when cells were treated with PBS.

\section{Agarose gel-retardation assay}

To investigate the interaction of PEG-SS-PLL with siVEGF, agarose gel electrophoresis was carried out at different weight ratios (Figure 2). The results showed that a significant interaction with siRNA was achieved from a weight ratio of 0.4:1 (lane 4), and complete complexation was observed at a weight ratio of 0.6:1 (lane 5) or above.

\section{Particle size and $\zeta$-potential measurements}

Proper size and surface charge are prerequisites for gene carriers. Diameters and $\zeta$-potentials of complexes formed at various weight ratios were measured by dynamic light scattering. As shown in Figure 3A, there was a similar trend in particle size tending to decrease with increased weight ratio; this suggested that siVEGF was not compactly condensed at lower weight ratios. At weight ratios higher than 0.2 , the particle size was around $220 \mathrm{~nm}$, which met the size requirements for efficient cellular endocytosis. From Figure 3B, we can see that the $\zeta$-potentials of the complex at various weight ratios increased with increased weight ratios. When the weight ratio of PEG-SS-PLL/siVEGF was less than 0.4, the complex exhibited negative potential, due to incomplete condensation of siVEGF. Once an excess of amines was available for particle formation, the final $\zeta$-potential gradually approached a plateau. These complexes with higher $\zeta$-potential were taken up easily by cells, due to electrostatic interactions between negatively charged cellular membranes and positively charged complexes.

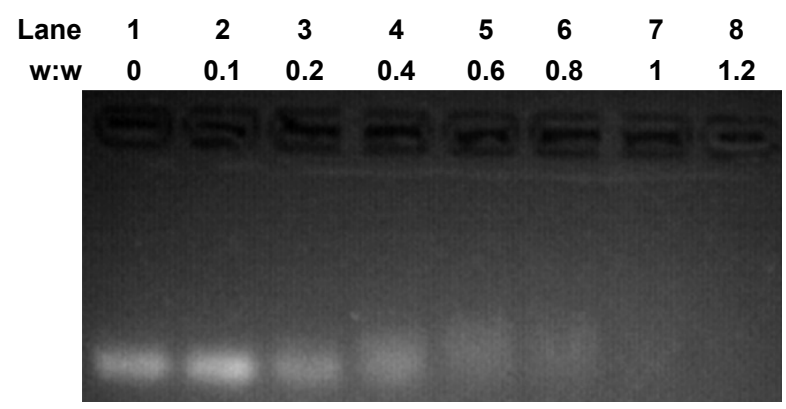

Figure 2 Agarose gel electrophoresis-retardation assay of PEG-SS-PLL/siRNA complex at different weight ratios.

Abbreviations: PEG-SS-PLL, polyethylene glycol-poly( $\varepsilon$-benzyloxycarbonyl-Llysine); siRNA, small interfering RNA. 

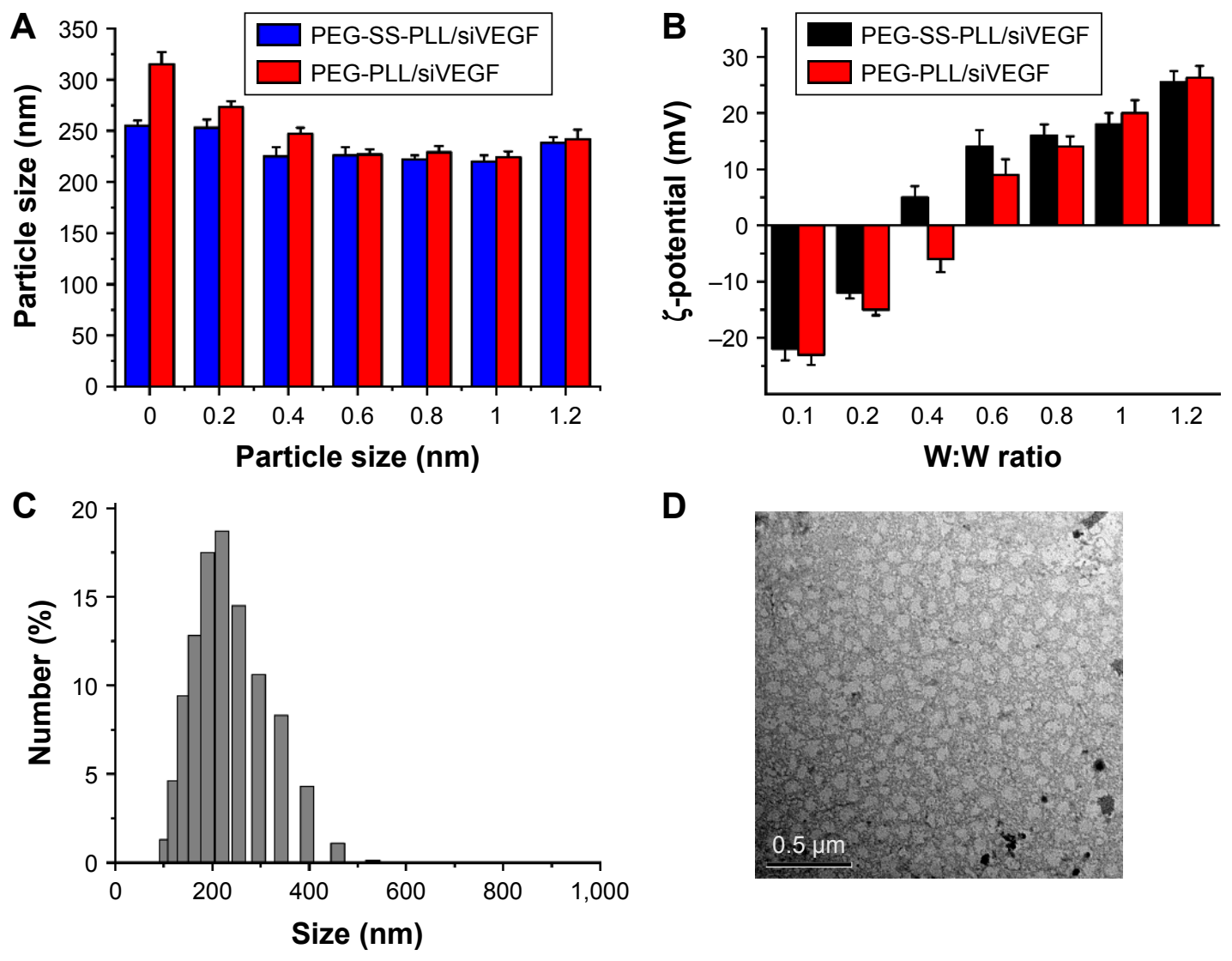

D

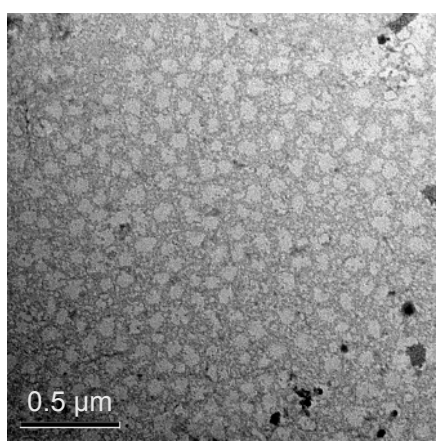

Figure 3 Particle size (A), $\zeta$-potential (B), size distribution (C), and representative TEM image (D) of PEG-PLL/siVEGF and PEG-SS-PLL/siVEGF complexes. Abbreviations: TEM, transmission electron microscopy; PEG-SS-PLL, polyethylene glycol-poly(e-benzyloxycarbonyl-L-lysine); siVEGF, small interfering VEGF RNA.

The morphology of the PEG-SS-PLL/siVEGF complex was observed by TEM. As shown in Figure 3D, typical images showed that particles were regularly spherical with a diameter around $200 \mathrm{~nm}$. This indicated a shrinkage effect caused by the evaporation of water during the TEM experiments.

\section{Effect of GSH on stability of PEG-SS-PLL/ siVEGF complex}

During the delivery process and controlled dissociation at the targeted site, a prerequisite for the efficient release of siVEGF and gene transfection is to maintain the structural integrity of the catiomer-siVEGF complex. Investigation of GSH-induced sensitivity was performed by measuring the size change in the PEG-SS-PLL/siVEGF complex in response to $10 \mathrm{mM} \mathrm{GSH}$ in PBS (10 mM, pH 7.4). As shown in Figure 4A, particle size in the PEG-SS-PLL/siVEGF complex was almost unchanged in the presence of $10 \%$ serum within 8 hours. However, as shown in Figure 4B, $10 \mathrm{mM}$ GSH rapidly induced a particle-size increase in the PEGSS-PLL/siVEGF complex, and large aggregates with sizes of over $600 \mathrm{~nm}$ were observed after 1.5 hours.

\section{Transfection efficiency of PEG-SS-PLL/ siVEGF complex}

Transfection efficiency was compared among siRNA alone and Lipofectamine/siVEGF, PEG-PLL/siVEGF, and PEGSS-PLL/siVEGF complexes. The results showed that the transfection efficiency of PEG-SS-PLL/siVEGF was the highest (Figure 5A-E). Quantitative cellular uptake of FAMlabeled siRNA was estimated using flow cytometry and further confirmed by fluorescence microscopy (Figure 5F). Maximal siRNA uptake efficiency was found in the PEGSS-PLL/siVEGF group (92.17\% $\pm 2.54 \%)$. However, there was little uptake detected in HepG2 cells treated with siRNA alone. Examination of mean fluorescence intensities of the cultured HepG2 cells with flow cytometry showed a similar trend in percentage of FAM-labeled siRNA-positive cells in the same treatment groups.

\section{Cell apoptosis detection by flow cytometry}

Cell apoptosis rate in the PEG-SS-PLL/siVEGF, PEG-PLL/ siVEGF, and the blank control groups was $48.21 \% \pm 4.25 \%$, 


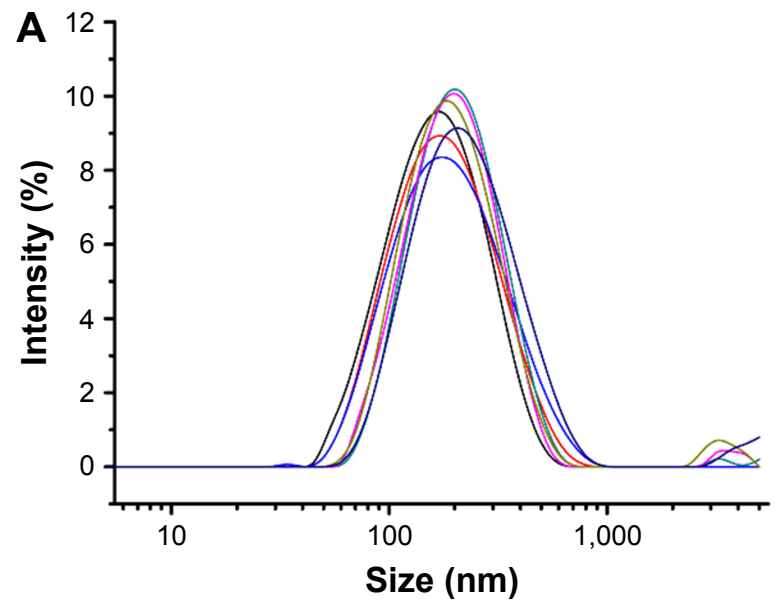

-0 hour -0.5 hour -1 hour -2 hours
-4 hours -6 hours -8 hours

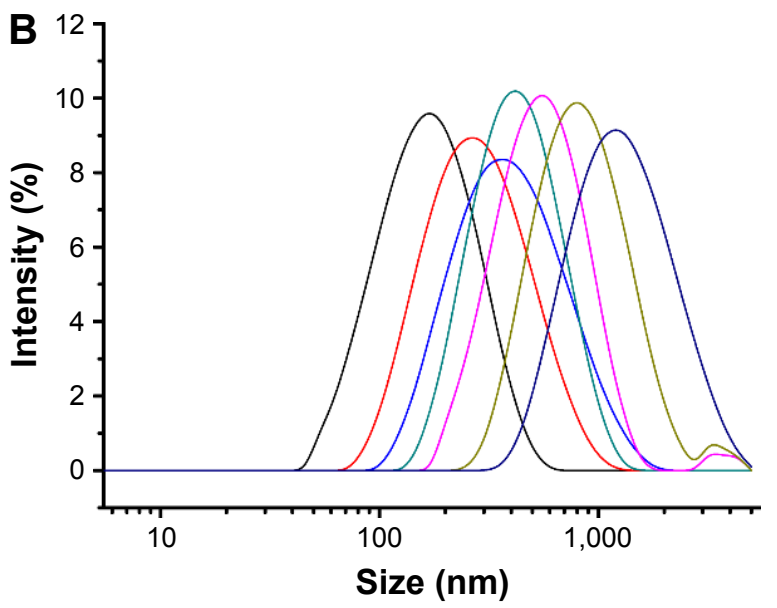

-0 hour -0.5 hour -1 hour -1.5 hours
-2 hours -2.5 hours -3 hours

Figure 4 Time-dependent size changes in PEG-SS-PLL/siVEGF complex with a diameter determined by dynamic light scattering.

Note: Eight hours storage (A); exposed to $10 \mathrm{mM}$ GSH (B).

Abbreviations: PEG-SS-PLL, polyethylene glycol-poly( $\varepsilon$-benzyloxycarbonyl-L-lysine); siVEGF, small interfering VEGF RNA; GSH, glutathione.
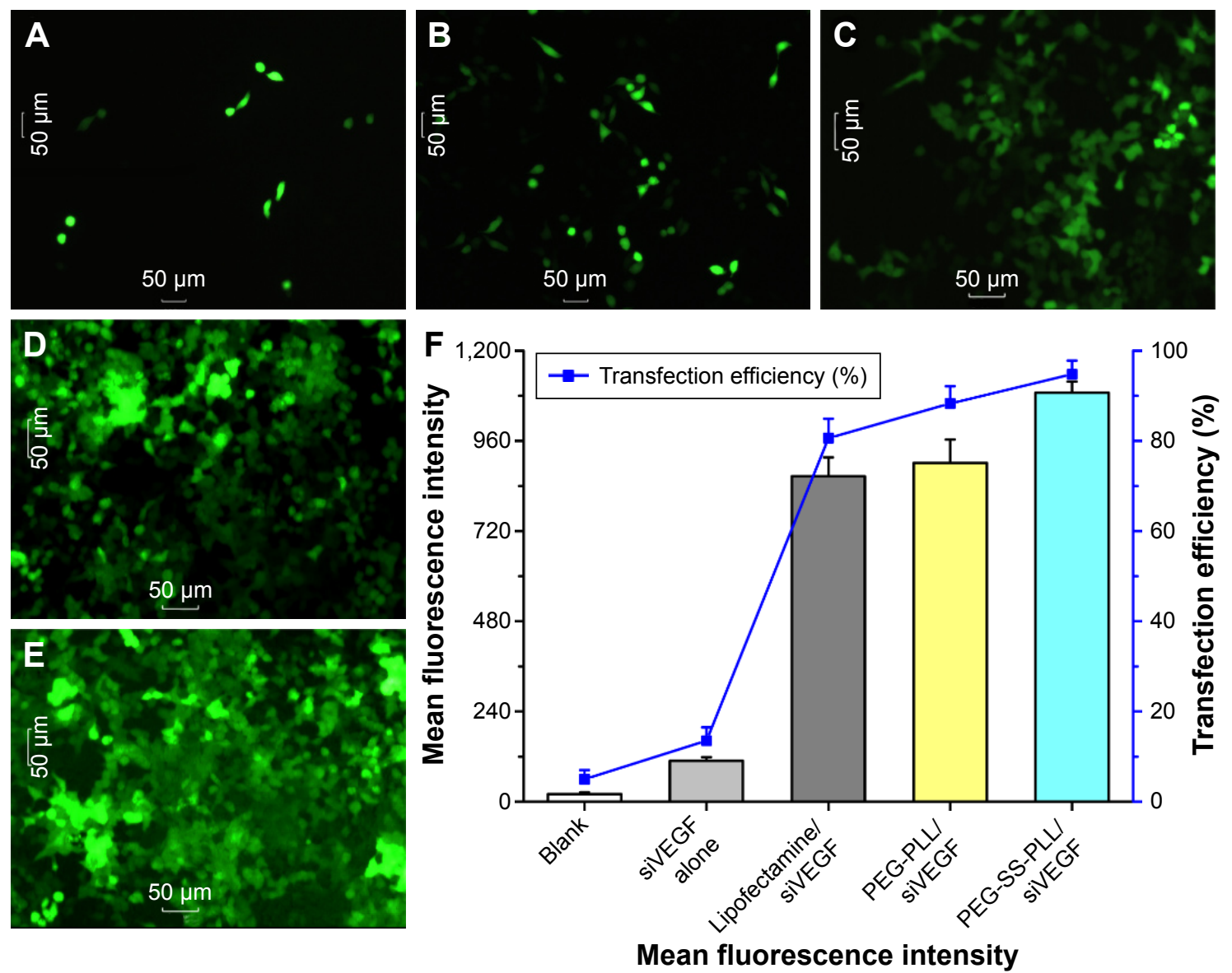

Figure 5 Transfection efficiency of PEG-SS-PLL as an siRNA delivery agent.

Notes: (A-E) Detection of transfection efficiency by fluorescence microscopy. High efficiency of transfection with fluorescent siRNA (green) in HepG2 cells was easily identified at 24 hours posttransfection (100X); (F) detection of transfection efficiency by flow cytometry. Transfection efficiency was up to $85 \%$ at 24 hours posttransfection. The histogram shows the enhanced FAM green fluorescence intensity of PEG-SS-PLL/siVEGF group compared to that of siRNA alone, Lipofectamine, and PEG-PLL/siVEGF. Fluorescence-microscopy images show FAM expression in HepG2 cells after silencing by PEG-SS-PLL and PEG-PLL complexes.

Abbreviations: PEG-SS-PLL, polyethylene glycol-poly(e-benzyloxycarbonyl-L-lysine); siRNA, small interfering RNA; siVEGF, VEGF siRNA. 
$8.67 \% \pm 0.4 \%$, and $8.64 \% \pm 0.28 \%$, respectively. This indicated that the cell apoptosis rate in the PEG-SS-PLL/siVEGF group was significantly higher than in the other two groups $(P<0.01$, Figure 6).

\section{Tumor model and in vivo siVEGF treatment}

To verify further whether the silencing was also effective in vivo, we intratumorally injected the PEG-SS-PLL/ siVEGF complex into HepG2 tumors in BALB/c mice to silence VEGF mRNA and observed a significant suppression of tumor growth by the PEG-SS-PLL/siVEGF complex compared to all the other groups $(P<0.05$, Figure 7$)$, thus indicating the successful delivery of siVEGF by PEGSS-PLL/siVEGF.

\section{Quantification of intracellular and intratumoral VEGF mRNA and protein}

Relative levels of intracellular and intratumoral VEGF mRNA were examined by real-time PCR (Figure 8A-D). Relative levels of intracellular and intratumoral proteins were observed by enzyme-linked immunosorbent assay (Figure 8E and F). Compared to all the other groups, expression levels of intracellular and intratumoral VEGF mRNA and protein decreased significantly in the PEG-SS-PLL/siVEGF group $(P<0.01)$. The gray scale in PEG-SS-PLL/siVEGF
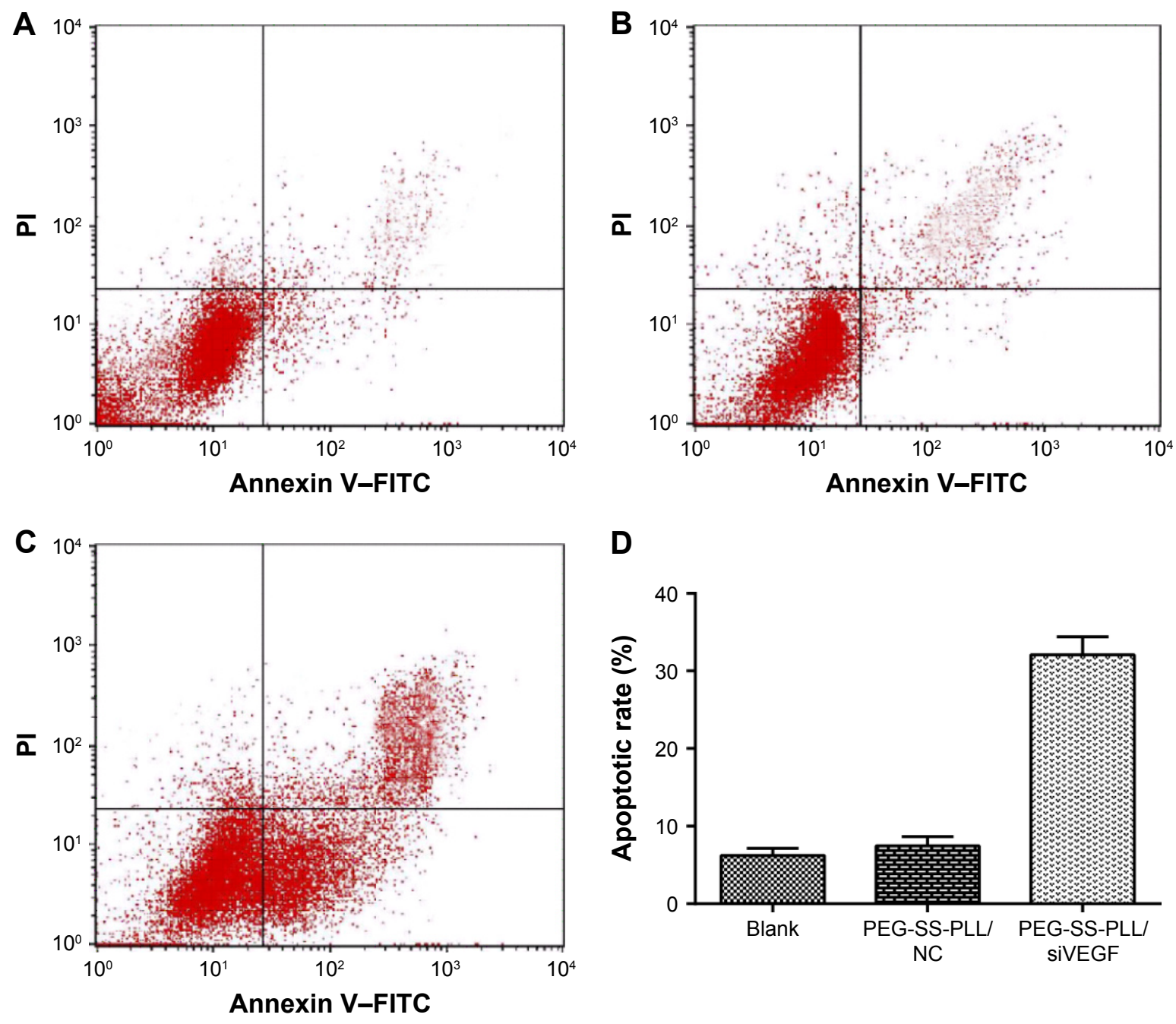

D

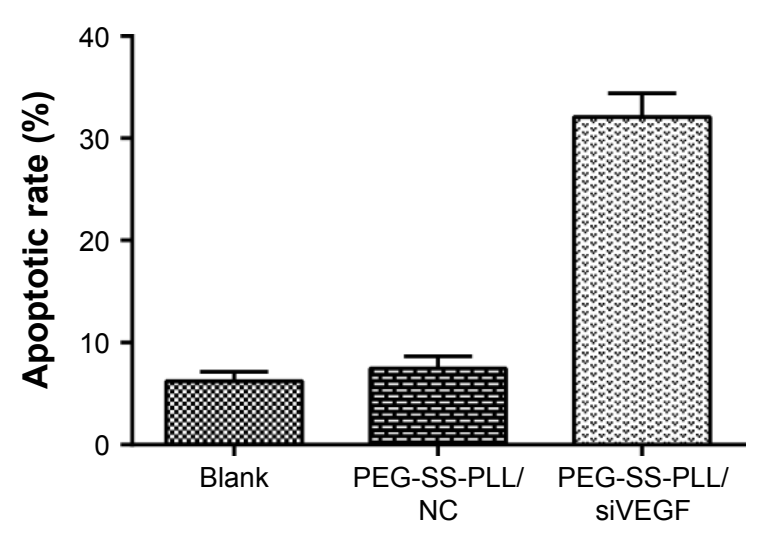

Figure 6 (A-D) Effect of PEG-SS-PLL/siVEGF gene knockdown on the apoptosis of HepG2 cells.

Notes: The results of flow cytometry are expressed as a dot plot, where the longitudinal coordinate was PI and the transverse coordinate was annexin V-FITC. Lower-left quadrants are the annexin $\mathrm{V}-\mathrm{FITC}^{-} \mathrm{PI}^{-}$double-negative cell group, representing normal cells, lower-right quadrants are the annexin $\mathrm{V}-\mathrm{FITC}^{+} \mathrm{Pl}^{-}$single-positive cell group, representing early apoptotic cells, and upper right quadrants are the annexin $\mathrm{V}-\mathrm{FITC}^{+} \mathrm{PI}^{+}$double-positive cell group, representing late apoptotic cells or dead cells. The results of flow cytometry are expressed as percentages. The degree of cell apoptosis was analyzed by annexin V-FITC/PI double staining. The extent of apoptotic cell death was quantified (D). Data are expressed as mean \pm SD for three individual experiments.

Abbreviations: PEG-SS-PLL, polyethylene glycol-poly(E-benzyloxycarbonyl-L-lysine); siVEGF, small interfering VEGF RNA; FITC, fluorescein isothiocyanate; PI, propidium iodide; SD, standard deviation. 


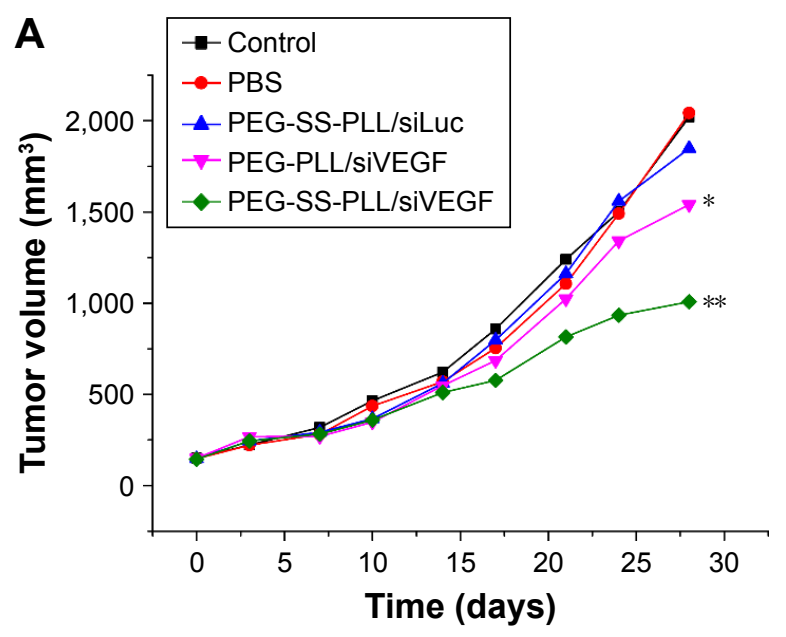

\section{B}

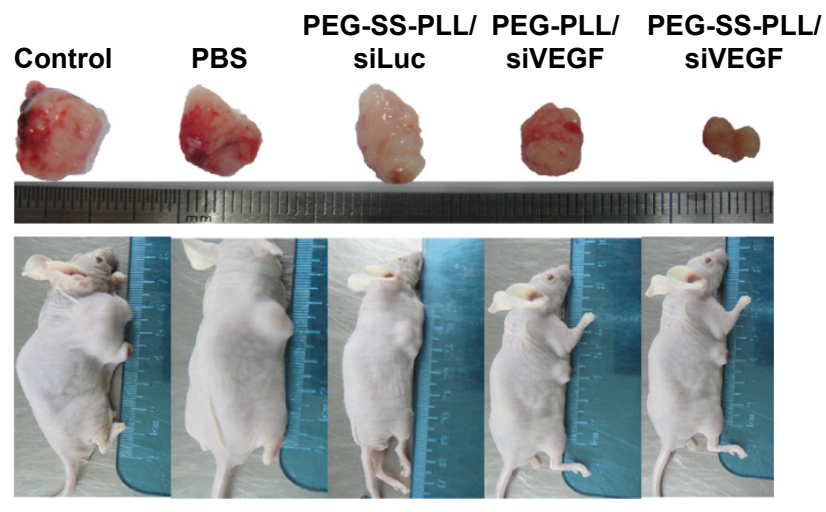

Figure 7 Effect of PEG-SS-PLL/siVEGF complex on tumor growth in vivo.

Notes: (A) Male BALB/c mice (five per group) with established HepG2 tumors were intravenously injected with the complex every other day five times. Tumor size was measured twice a week. Data are shown as mean $\pm \mathrm{SD}, \mathrm{n}=5$. $* \mathrm{P}<0.05, * * \mathrm{P}<0.0 \mathrm{l}$ for PEG-SS-PLL/siVEGF versus control group. (B) Representative images show that the tumors in the PEG-SS-PLL/siVEGF group were remarkably smaller on the day 28 after tumor cell inoculation than those of the PBS, PEG-SS-PLL/siLuc, and PEGPLL/siVEGF groups.

Abbreviations: PEG-SS-PLL, polyethylene glycol-poly(E-benzyloxycarbonyl-L-lysine); siVEGF, small interfering VEGF RNA; SD, standard deviation; PBS, phosphatebuffered saline.

decreased significantly when compared with all the other groups $(P<0.01)$.

\section{Immunohistochemistry analysis}

To observe the therapeutic efficiency of complexes in tumors, tumor sections were stained with hematoxylin and eosin, VEGF, or CD31 (Figure 9). VEGF or CD31 expression was not significantly decreased in the PBS group or the PEG-SS-PLL/siLuc group. VEGF or CD31 expression was moderately decreased in the PEG-PLL/siVEGF group, but VEGF or CD31 expression was remarkably decreased in the PEG-SS-PLL/siVEGF group.

\section{Discussion}

It has been mentioned in recent literature that the stability and biocompatibility of nanoparticles in circulation could be improved greatly by PEG modification; ${ }^{33}$ however, PEGylation can inhibit the intracellular trafficking of nanoparticles, especially in cellular uptake and subsequent endosome escape. Therefore, it will lead to significant loss of activity, and this is referred to as the "PEG dilemma". ${ }^{34}$ Researchers have designed various types of novel copolymers, such as $\mathrm{pH}$-sensitive, temperature-sensitive, light-sensitive, magnetic-sensitive, ultrasound-sensitive, redox-sensitive, and enzyme-degraded copolymers, in order to solve the issue of low transfection efficiency of the PEGylated nanoparticles. ${ }^{35-38}$

In this study, redox-sensitive PEG-SS-PLL was synthesized and used to deliver the novel nanoparticle complex
PEG-SS-PLL/siVEGF. We investigated the transfection efficiency, cytotoxicity in vitro, tumor-inhibitory effect in vivo, and the mechanism of antitumor effect of the complex. It was found that PEG-SS-PLL was such a highly effective vector for siVEGF delivery that it reduced VEGF mRNA and protein expression in vitro and in vivo, thus inhibiting HCC tumor growth.

In this study, we found that HepG2 cell viability after transfection with PEG-SS-PLL/siVEGF was significantly higher than after transfection with PEI/siVEGF or Lipofectamine/siVEGF. Furthermore, both PEGSS-PLL/siVEGF and PEG-PLL/siVEGF complexes showed extremely low toxicity to HepG2 cells, even at the concentration of $200 \mathrm{nM}$. This is a match with previous literature, where it has been reported that siVEGF with nonPEG-SS-PLL vectors had low toxicity at a concentration of $200 \mathrm{nM}^{27}$

The novel biodegradable PEG-SS-PLL catiomer significantly improved transfection efficiency up to $96 \%$, markedly higher than previous studies $(81.3 \%)^{2,39}$ The catiomer delivered siVEGF into tumor cells more efficiently, because aggregates formed due to reductive cleavage of the intermediate disulfide bonds and resulted in the shedding of the PEG layers. These results indicated that the PEG-SS-PLL is highly promising for controlled and efficient release of siVEGF. This is in accordance with a previous study where the catiomer effectively delivered plasmid DNA into tumor cells and improved the release efficiency of doxorubicin under optimized conditions in vitro. ${ }^{4}$ The higher transfection 

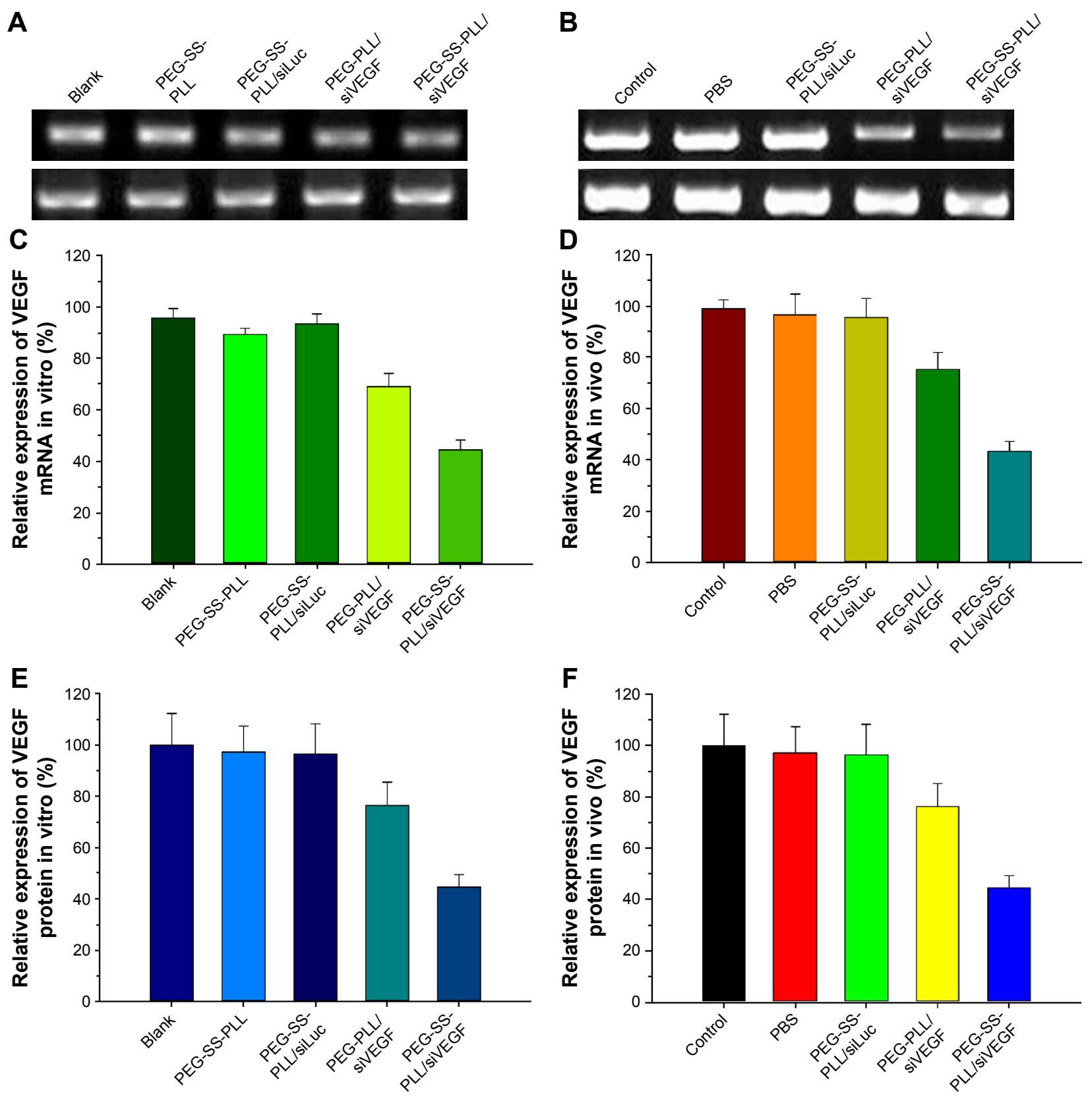

Figure 8 Relative levels of VEGF.

Notes: (A, C) VEGF mRNA by real-time PCR in vitro and (B, D) in vivo; (E) VEGF protein by ELISA in vitro and (F) in vivo.

Abbreviations: mRNA, messenger RNA; PCR, polymerase chain reaction; ELISA, enzyme-linked immunosorbent assay; PEG-SS-PLL, polyethylene glycol-poly( $\varepsilon$ benzyloxycarbonyl-L-lysine); siVEGF, small interfering VEGF RNA; PBS, phosphate-buffered saline.

efficiency of PEG-SS-PLL could be attributed to the water-soluble PEG, which formed a protective layer on the nanoparticle-complex surfaces to prevent degradation from protease. Later, the PEG dilemma in nanoparticle intracellular trafficking was avoided, since the PEG in PEG-PLL was not able to shed. The studies revealed that the concentration of GSH was different between the inside and the outside of tumor cells, and intracellular concentration of GSH in tumors was dramatically higher than normal extracellular fluid and cytoplasm. ${ }^{40-42}$ It has also been reported in the literature that the recurrence rate was decreased significantly when the VEGF inhibitor was used to treat HCC. ${ }^{43,44}$ The antitumor efficacy of PEG-SS-PLL/siVEGF was much higher in our study.

\section{Conclusion}

In summary, our research showed that PEG-SS-PLL delivered siVEGF efficiently, and the complex significantly 


\section{A}
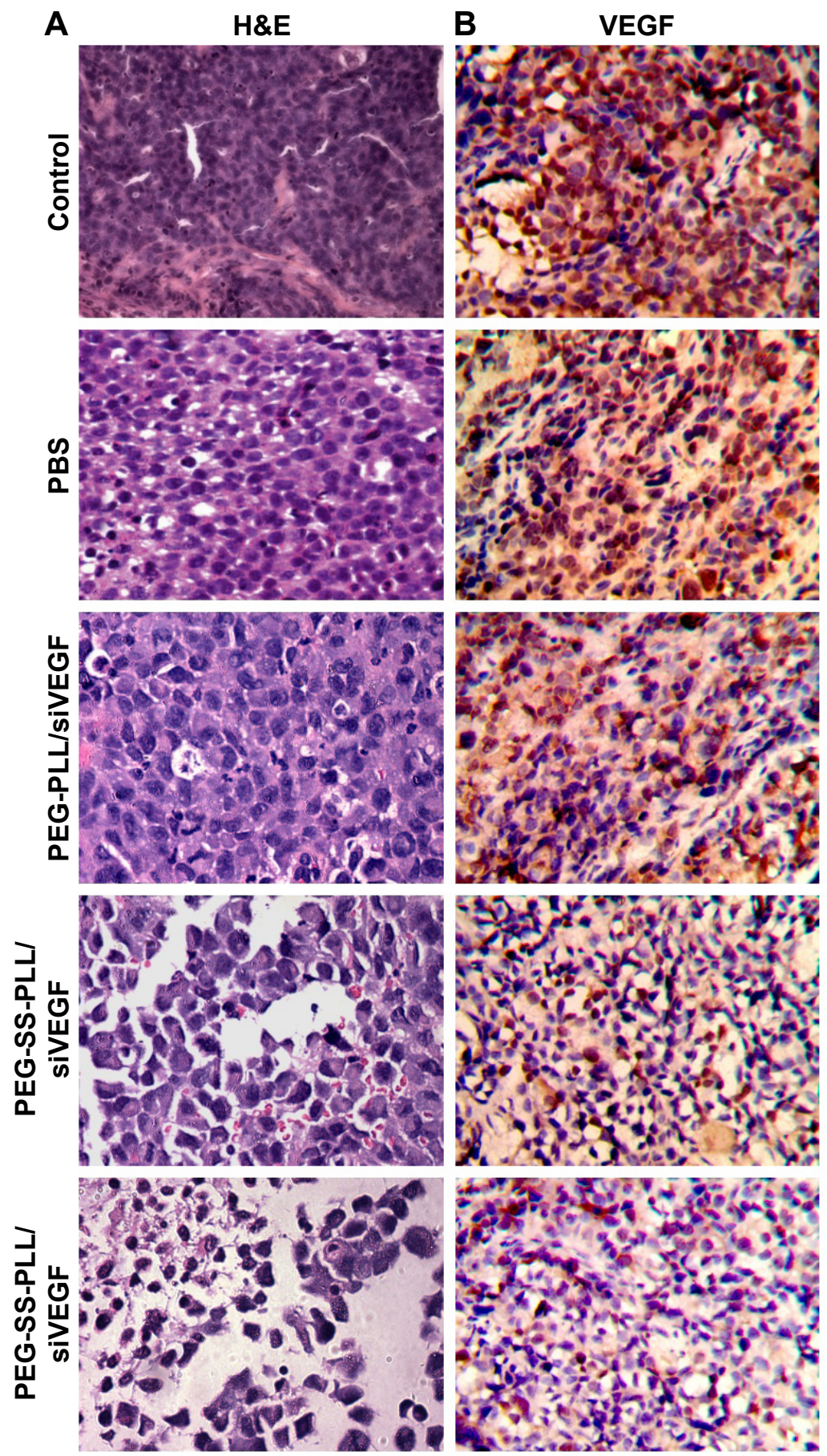
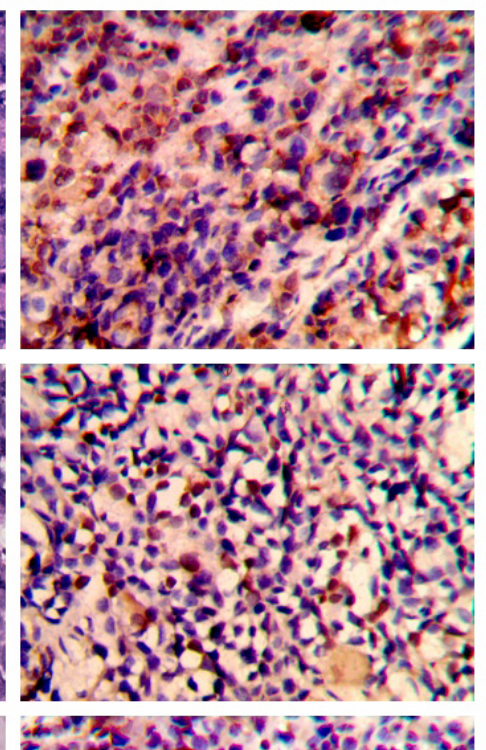
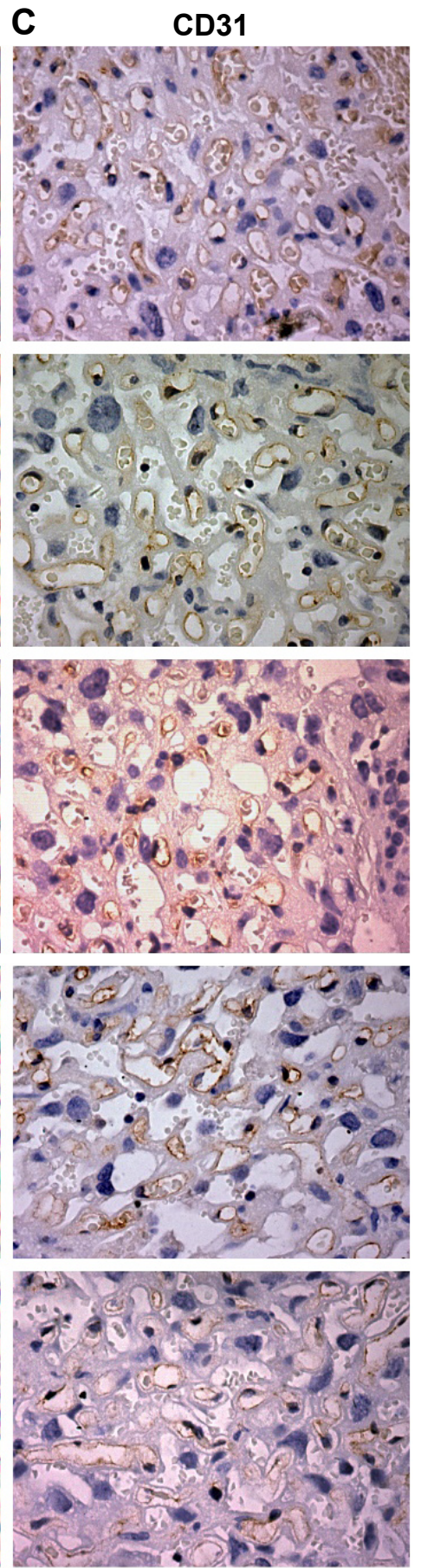

Figure 9 Tumor growth and expression of VEGF and CD3I by immunohistochemistry

Notes: Tumor-bearing mice were killed 28 days after initial injection, then tumor tissues were collected and processed for paraffin-embedded sections and immunohistochemical staining $(n=5)$. Brown staining in the tissue sections shows positive expression of VEGF or CD3I. Images 400X. (A) H\&E staining shows inhibition of tumor growth after intravenous tail injection of PEG-SS-PLL/siVEGF complex compared to control, PBS, PEG-SS-PLL/siLuc, and PEG-PLL/siVEGF groups; (B) VEGF staining shows levels of different types of VEGF-protein expression; (C) CD3I staining shows levels of CD3I-protein expression, in contrast to control, PBS, PEG-SS-PLL/siLuc, and PEG-PLL/siVEGF groups. Abbreviations: H\&E, hematoxylin and eosin; PEG-SS-PLL, polyethylene glycol-poly( $\varepsilon$-benzyloxycarbonyl-L-lysine); siVEGF, small interfering VEGF RNA; mRNA, messenger RNA; PCR, polymerase chain reaction; ELISA, enzyme-linked immunosorbent assay; PBS, phosphate-buffered saline.

reduced VEGF mRNA and protein expression in vitro and in vivo, thus inhibiting tumor growth in vivo. Therefore, PEG-SS-PLL might be an effective nonviral siVEGF vector for antiangiogenesis gene therapy.

\section{Acknowledgment}

This work was financially supported by the National Natural Science Foundation of China (81171297/H0928 and 81071201/H1808). 


\section{Disclosure}

The authors report no conflicts of interest in this work.

\section{References}

1. Villanueva A, Llovet JM. Targeted therapies for hepatocellular carcinoma. Gastroenterology. 2011;140(5):1410-1426.

2. Gao J, Yu Y, Zhang Y, et al. EGFR-specific PEGylated immunoliposomes for active siRNA delivery in hepatocellular carcinoma. Biomaterials. 2012;33(1):270-282.

3. Zhang L, Wang JN, Tang JM, et al. VEGF is essential for the growth and migration of human hepatocellular carcinoma cells. Mol Biol Rep. 2012;39(5):5085-5093.

4. Calvisi DF, Frau M, Tomasi ML, Feo F, Pascale RM. Deregulation of signalling pathways in prognostic subtypes of hepatocellular carcinoma: novel insights from interspecies comparison. Biochim Biophys Acta. 2012;1826(1):215-237.

5. Yang ZF, Poon RT. Vascular changes in hepatocellular carcinoma. Anat Rec (Hoboken). 2008;291(6):721-734.

6. Murata N, Takashima Y, Toyoshima K, Yamamoto M, Okada H. Anti-tumor effects of anti-VEGF siRNA encapsulated with PLGA microspheres in mice. J Control Release. 2008;126(3):246-254.

7. Hatakeyama $\mathrm{H}$, Akita $\mathrm{H}$, Harashima $\mathrm{H}$. A multifunctional envelope type nano device (MEND) for gene delivery to tumours based on the EPR effect: a strategy for overcoming the PEG dilemma. Adv Drug Deliv Rev. 2011;63(3):152-160.

8. Kuai R, Yuan W, Qin Y, et al. Efficient delivery of payload into tumor cells in a controlled manner by TAT and thiolytic cleavable PEG comodified liposomes. Mol Pharm. 2010;7(5):1816-1826.

9. Moon WS, Rhyu KH, Kang MJ, et al. Overexpression of VEGF and angiopoietin 2 : a key to high vascularity of hepatocellular carcinoma? Mod Pathol. 2003;16(6):552-557.

10. Riehemann K, Schneider SW, Luger TA, Godin B, Ferrari M, Fuchs H. Nanomedicine: challenge and perspectives. Angew Chem Int Ed Engl. 2009;48(5):872-897.

11. Fernando NH, Hurwitz HI. Inhibition of vascular endothelial growth factor in the treatment of colorectal cancer. Semin Oncol. 2003; 30(3 Suppl 6):39-50.

12. Fire A, Xu S, Montgomery MK, Kostas SA, Driver SE, Mello CC. Potent and specific genetic interference by double-stranded RNA in Caenorhabditis elegans. Nature. 1998;391(6669):806-811.

13. McNamara JO 2nd, Andrechek ER, Wang Y, et al. Cell type-specific delivery of siRNAs with aptamer-siRNA chimeras. Nat Biotechnol. 2006;24(8):1005-1015.

14. Davis ME, Zuckerman JE, Choi CH, et al. Evidence of RNAi in humans from systemically administered siRNA via targeted nanoparticles. Nature. 2010;464(7291):1067-1070.

15. Peer D, Park EJ, Morishita Y, Carman CV, Shimaoka M. Systemic leukocyte-directed siRNA delivery revealing cyclin D1 as an antiinflammatory target. Science. 2008;319(5863):627-630.

16. Kumar P, Ban HS, Kim SS, et al. T cell-specific siRNA delivery suppresses HIV-1 infection in humanized mice. Cell. 2008;134(4):577-586.

17. Kim SH, Jeong JH, Lee SH, Kim SW, Park TG. Local and systemic delivery of VEGF siRNA using polyelectrolyte complex micelles for effective treatment of cancer. J Control Release. 2008;129(2): $107-116$.

18. Raskopf E, Vogt A, Sauerbruch T, Schmitz V. siRNA targeting VEGF inhibits hepatocellular carcinoma growth and tumor angiogenesis in vivo. J Hepatol. 2008;49(6):977-984.

19. Wu HP, Feng GS, Liang HM, Zheng CS, Li X. Vascular endothelial growth factor antisense oligodeoxynucleotides with lipiodol in arterial embolization of liver cancer in rats. World $J$ Gastroenterol. 2004;10(6):813-818.

20. Owens DE 3rd, Peppas NA. Opsonization, biodistribution, and pharmacokinetics of polymeric nanoparticles. Int J Pharm. 2006;307(1): 93-102.
21. Venkataraman S, Ong WL, Ong ZY, Loo SC, Ee PL, Yang YY. The role of PEG architecture and molecular weight in the gene transfection performance of PEGylated poly(dimethylaminoethyl methacrylate) based cationic polymers. Biomaterials. 2011;32(9):2369-2378.

22. Schiffelers RM, Ansari A, Xu J, et al. Cancer siRNA therapy by tumor selective delivery with ligand-targeted sterically stabilized nanoparticle. Nucleic Acids Res. 2004;32(19):e149.

23. Takae S, Miyata K, Oba M, et al. PEG-detachable polyplex micelles based on disulfide-linked block catiomers as bioresponsive nonviral gene vectors. J Am Chem Soc. 2008;130(18):6001-6009.

24. Cerritelli S, Velluto D, Hubbell JA. PEG-SS-PPS: reduction-sensitive disulfide block copolymer vesicles for intracellular drug delivery. Biomacromolecules. 2007;8(6):1966-1972.

25. Clawson C, Ton L, Aryal S, Fu V, Esener S, Zhang L. Synthesis and characterization of lipid-polymer hybrid nanoparticles with $\mathrm{pH}-$ triggered poly(ethylene glycol) shedding. Langmuir. 2011;27(17): 10556-10561.

26. Wen HY, Dong HQ, Xie WJ, et al. Rapidly disassembling nanomicelles with disulfide-linked PEG shells for glutathione-mediated intracellular drug delivery. Chem Commun. 2011;47(12):3550-3552.

27. Cai X, Dong C, Dong H, et al. Effective gene delivery using stimulusresponsive catiomer designed with redox-sensitive disulfide and acidlabile imine linkers. Biomacromolecules. 2012;13(4):1024-1034.

28. Cai X, Zhu H, Dong H, Li Y, Su J, Shi D. Suppression of VEGF by reversible-PEGylated histidylated polylysine in cancer therapy. $A d v$ Healthc Mater. 2014;3(11):1818-1827.

29. Falamarzian A, Xiong XB, Uludag H, Lavasanifar A. Polymeric micelles for siRNA delivery. J Drug Deliv Sci Technol. 2012;22(1):43-54.

30. Ping Y, Liu C, Zhang Z, Liu KL, Chen J, Li J. Chitosan-graft-(PEI$\beta$-cyclodextrin) copolymers and their supramolecular PEGylation for DNA and siRNA delivery. Biomaterials. 2011;32(32):8328-8341.

31. Silverman J, Suckow MA, Murthy S. The IACUC Handbook. 3rd ed. Boca Raton (FL): CRC Press; 2014.

32. National Research Council. Guide for the Care and Use of Laboratory Animals. 8th ed. Washington: National Academies Press; 2010.

33. Liu P, Yu H, Sun Y, Zhu M, Duan Y. A mPEG-PLGA-b-PLL copolymer carrier for adriamycin and siRNA delivery. Biomaterials. 2012;33(17):4403-4412.

34. Gartel AL, Kandel ES. RNA interference in cancer. Biomol Eng. 2006; 23(1):17-34.

35. Akhtar S, Benter I. Toxicogenomics of non-viral drug delivery systems for RNAi: potential impact on siRNA-mediated gene silencing activity and specificity. Adv Drug Deliv Rev. 2007;59(2-3):164-182.

36. Biswal BK, Debata NB, Verma RS. Development of a targeted siRNA delivery system using FOL-PEG-PEI conjugate. Mol Biol Rep. 2010;37(6):2919-2926.

37. Deng J, Gao N, Wang Y, et al. Self-assembled cationic micelles based on PEG-PLL-PLLeu hybrid polypeptides as highly effective gene vectors. Biomacromolecules. 2012;13(11):3795-3804.

38. Kurihara R, Pissuwan D, Mori T, Katayama Y, Niidome T. Biodistribution and tumor localization of PEG-modified dendritic poly(L-lysine) oligonucleotide complexes. J Biomater Sci Polym Ed. 2012;23(18): 2369-2380.

39. Zhang H, Jia X, Han F, et al. Dual-delivery of VEGF and PDGF by double-layered electrospun membranes for blood vessel regeneration. Biomaterials. 2013;34(9):2202-2212.

40. Chao Y, Li CP, Chau GY, et al. Prognostic significance of vascular endothelial growth factor, basic fibroblast growth factor, and angiogenin in patients with resectable hepatocellular carcinoma after surgery. Ann Surg Oncol. 2003;10(4):355-362.

41. Hicklin DJ, Ellis LM. Role of the vascular endothelial growth factor pathway in tumor growth and angiogenesis. J Clin Oncol. 2005;23(5): 1011-1027.

42. Poon RT, Ho JW, Tong CS, Lau C, Ng IO, Fan ST. Prognostic significance of serum vascular endothelial growth factor and endostatin in patients with hepatocellular carcinoma. Br J Surg. 2004;91(10):1354-1360. 
43. Remaut K, Lucas B, Braeckmans K, Demeester J, De Smedt SC. Pegylation of liposomes favours the endosomal degradation of the delivered phosphodiester oligonucleotides. J Control Release. 2007; 117(2):256-266.
44. Remaut K, Symens N, Lucas B, Demeester J, De Smedt SC. Efficient delivery of intact phosphodiester oligonucleotides by poly- $\beta$-amino esters. J Control Release. 2010;144(1):65-74.

\section{Publish your work in this journal}

The International Journal of Nanomedicine is an international, peerreviewed journal focusing on the application of nanotechnology in diagnostics, therapeutics, and drug delivery systems throughout the biomedical field. This journal is indexed on PubMed Central, MedLine, CAS, SciSearch ${ }^{\circledR}$, Current Contents ${ } /$ Clinical Medicine,
Journal Citation Reports/Science Edition, EMBase, Scopus and the Elsevier Bibliographic databases. The manuscript management system is completely online and includes a very quick and fair peer-review system, which is all easy to use. Visit http://www.dovepress.com/ testimonials.php to read real quotes from published authors.

Submit your manuscript here: http://www.dovepress.com/international-journal-of-nanomedicine-journal 